\title{
Management of an esophageal metallic stent obstructed by tumor progression: endoscopic alcohol injection therapy instead of restenting
}

We report here a patient in whom an esophageal metallic stent was obstructed by tumor progression. The obstruction was treated successfully by endoscopic alcohol injection.

A 74-year-old man was diagnosed as having nonresectable esophageal cancer. An esophageal self-expanding covered metallic stent was implanted, but 5 months later the patient complained of inability to swallow fluids and saliva. Upper gastrointestinal endoscopy revealed a stent opening of 5-6 mm ( Fig. 1), with the proximal end of the esophageal metallic stent obstructed by malignant tumor progression.

We injected a total of $20 \mathrm{~mL}$ of $98 \%$ alcohol across the four quadrants of the esophagus. The postintervention course was uneventful and the patient started oral intake of food on day 2 after the procedure. A follow-up endoscopic examination carried out 10 days after the procedure revealed a fully patent esophagus (๑ Fig. 2).

The patency of the esophagus was adequate at further endoscopic follow-up 2 months later.

Covered metallic stents are increasingly used to prevent obstruction of the stent lumen by tumor progression [1 - 3]. However, the distal or the proximal end of an esophageal stent may also be obstructed due to tumor infiltration, as found in our patient. The general approach to management in such cases is implantation of a second stent [4]. However, insertion of stent is a costly procedure, requiring an experienced operator, and is associated with increased risk of stent-related complications such as esophageal perforation, aspiration pneumonia, bleeding, and severe retrosternal pain [5]. Obstruction of either end of a stent usually occurs over a short segment of the stent. It is easy to inject alcohol into the tumor tissue without prior dilatation. In our experience no serious complication was ob-

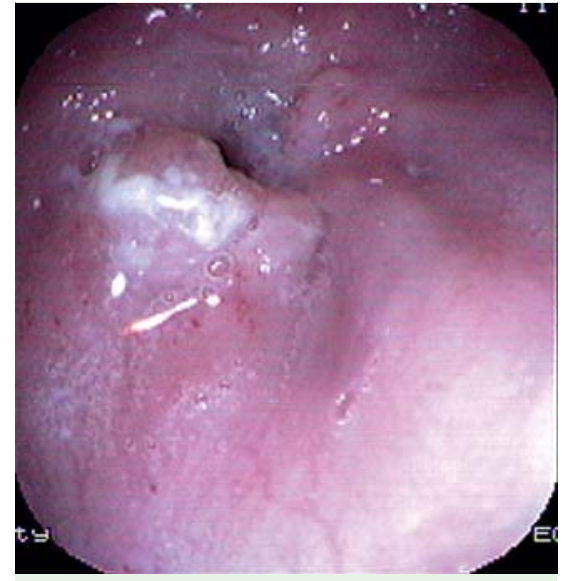

Fig. 1 Pretreatment endoscopic view showing severe narrowing of the proximal end of the esophageal metallic stent because of the infiltrating esophageal cancer.

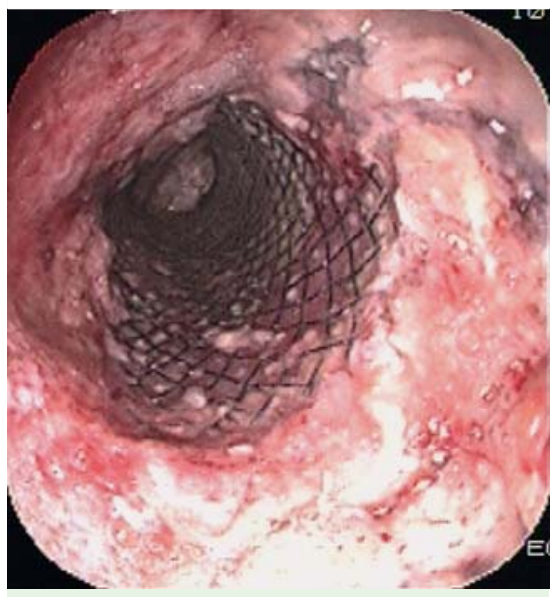

Fig. 2 Posttreatment endoscopic view showing the patent esophagus, which depended on necrosis of the tumor after alcohol injection treatment. The previously placed stent is also seen.

served. In conclusion, endoscopic alcohol injection therapy is a cost-effective, easily carried out alternative to restenting in a patient with obstruction of an esophageal stent by tumor progression.

Endoscopy_UCTN_Code_TTT_1AO_2AZ
B. Ozdil' ', C. Kece' ${ }^{2}$, H. Akkiz'

M. Sandikci ${ }^{1}$, A. Cosar ${ }^{3}$

1 Cukurova University, Faculty of Medicine, Department of Gastroenterology,

Adana, Turkey

2 Department of Gastroenterologic Surgery, Research Hospital, Trabzon, Turkey

3 Karadeniz Technical University, Faculty of Medicine, Department of Gastroenterology, Trabzon, Turkey

\section{References}

1 Raijman I, Siddique I, Ajani J et al. Palliation of malignant dysphagia and fistulae with coated expandable metal stents: experience with 101 patients. Gastrointest Endosc 1998; 48: 172 - 179

2 Homs MY, Kuipers EJ, Siersema PD. Palliative therapy. J Surg Oncol 2005; 92 (Suppl 3): 246- 256

3 Vakil N, Morris AI, Marcon N et al. A prospective, randomized, controlled trial of covered expandable metal stents in the palliation of malignant esophageal obstruction at the gastroesophageal junction. Am J Gastroenterol 2001; 96: 1791 - 1796

4 Homs MY, Steyerberg EW, Kuipers EJ et al. Causes and treatment of recurrent dysphagia after self-expanding metal stent placement for palliation of esophageal carcinoma. Endoscopy 2004; 36: 880-886

5 Baron TH. Expandable metal stents for the treatment of cancerous obstruction of the gastrointestinal tract. N Engl J Med 2001; 344: $1681-1687$

Bibliography

DOI 10.1055/s-0029-1243909

Endoscopy 2010; 42: E91

(c) Georg Thieme Verlag KG Stuttgart - New York . ISSN 0013-726X

Corresponding author

B. Ozdil, MD

Cukurova University

Gastroenterology Division, Balcali Hospital

Yuregir

Adana 01330

Turkey

burhanozdil@gmail.com 